\title{
Parametric Approach to Geo-Ecological Studies of Hydrocarbon Development in the Offshore Area of the Caspian Sea
}

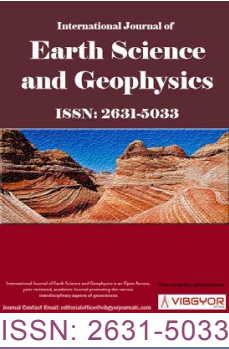

\section{Bukharitsin $\mathrm{P}^{1,2,3^{*}}$, Bukharitsin $A P^{4}$, Ivanov $A Y^{2}{ }^{2}$, Gindiev $M A^{5}$, Eldarov $E M^{6}$ and Golubov $B N^{2}$}

${ }^{1}$ Institute of Water Problems, Russian Academy of Sciences, Moscow, Russia

2Institute of Oceanology, Russian Academy of Sciences, Moscow, Russia

${ }^{3}$ Astrakhan State Technical University, Astrakhan, Russia

"Moscow Financial and Industrial University "Synergy", Moscow, Russia

5"Rosneft-Dagneft" OJSC, Yuzhno-Sukhokumsk, Russia

${ }^{6}$ Dagestan State University, Russia

\begin{abstract}
Annotation
The authors of the article consider the Caspian Sea as a geophysical mass in the form of a relatively thin layer of water above the structural levels of the Pliocene-Quaternary deposits, which is influenced by the following environmental opposite factors: On the one hand, geological and, on the other, climatic and hydrological. The parametric approach to the study of the driving forces of the environmental development of the Caspian sea is based on the analysis of natural disasters over the past 70 years in the areas of off shore hydrocarbon production: Powerful release of the earth's crust fluids (groundwater, mud, oil and gas) and catastrophic ice processes in the northern part of the Caspian sea. This work contributes to the improvement of the theoretical foundations of geo-ecological and ecological-economic studies of offshore oil and gas developments, as well as contributes to raising public awareness in the problems of preventing accidents on oil platforms and the prevention of pollution of marine environment.
\end{abstract}

\section{Keywords}

The Caspian Sea, Natural disasters, Fluids, Ice ridges, Oil fields, Oil production platforms

\section{Introduction}

The Caspian Sea is the largest land locked body of water on Earth, located in the inner region of Eurasia, which was isolated in the Middle Pliocene about 5-6 million years ago. The body of water rests on a multi-kilometer thickness of water-, oil- and gas-saturated rocks of three groups of sedimentary oil and gass-bearing basins: North, Middle and South Caspian. The Caspian Sea is characterized by the presence of large reserves of non-renewable fuel and energy resources, a unique ichthyofauna, and also a coastal environment favorable for the

*Corresponding author: Bukharitsin Pl, Institute of Water Problems; Institute of Oceanology, Russian Academy of Sciences, Moscow, Russia; Astrakhan State Technical University, Astrakhan, Russia Accepted: August 13, 2020; Published: August 15, 2020

Copyright: (C) 2020 Bukharitsin PI, et al. This is an open-access article distributed under the terms of the Creative Commons Attribution License, which permits unrestricted use, distribution, and reproduction in any medium, provided the original author and source are credited.

Bukharitsin PI, et al. Int J Earth Sci Geophys 2020, 6:036

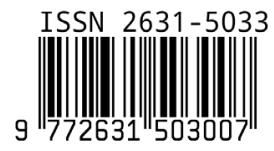




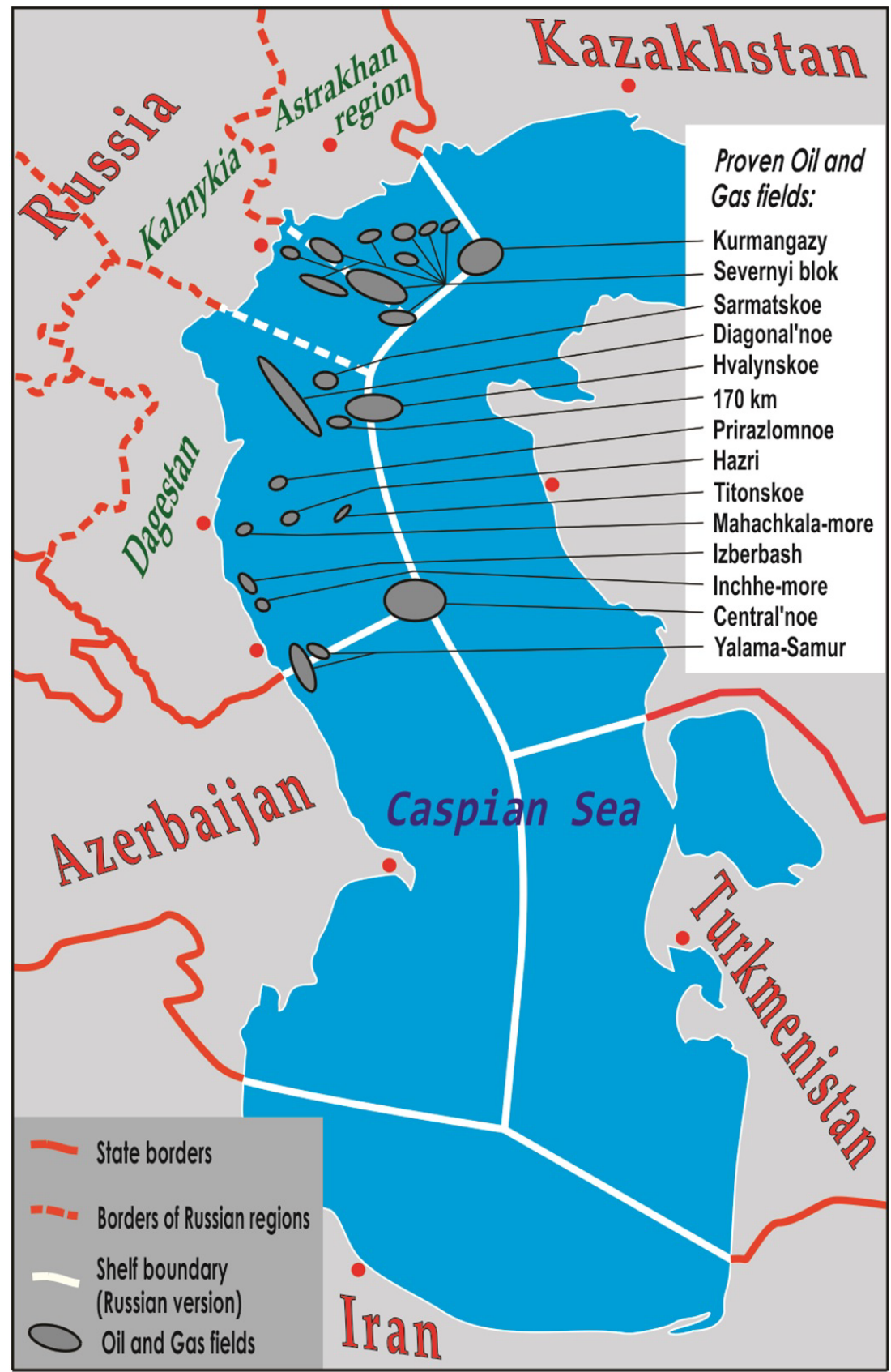

Figure 1: The most promising sites of mineral recourses management in the Russian zone of the Caspian shelf. (Map compiled by the authors according to [1,22]).

development of resorts and tourism. In its depths, including in the Russian zone of the Caspian shelf, various types of ore and nonmetallic minerals are concentrated [1]. Among the latter, oil and gas deposits are of particular value (Figure 1).

However, the use of these resources can be seriously complicated by a number of dangerous natural phenomena and processes [2-9]. The latter in this study are considered as parametric factors that can significantly change the ecological balance of the entire Caspian water reservoir.

\section{Research Concept}

The Caspian Sea as an integral geophysical system: A traditional and new approaches to research. The traditional approach comes down to the notion that has been deeply rooted since the $18^{\text {th }}$ century that this sea as a closed drainless water body with an impenetrable bottom, the water balance of which is mainly regulated only by climate, i.e. ratio of river runoff and evaporation losses. Therefore, the mechanisms of adaptation of the inhabitants of the Caspian sea to abiotic environmental factors 
are seen in the action of only exogenous processes caused by the radiant energy of the Sun, the circulation of sea water and air masses, the work of surface waters flowing into it, the vital activity of organisms, etc. Accordingly, a scientific assessment of the impact of centuries-long economic activity on the state of the Caspian sea mainly comes down to the analysis of chemical property and surface water regime. This creates a misconception that the supposedly "zero discharge" of anthropogenic pollutants is able to ensure the purity of the waters of the Caspian and thereby save the inhabitants of this sea, including seals, from extinction. The disadvantage of this point of view is that the lithosphere here is almost completely excluded from the abiotic and social links of the Caspian ecosystem.

A new parametric approach fills this gap focusing on the dialectics of the manifestation of geological and climatic-hydrological processes [10]. In this case we are talking about processes of a completely different geophysical nature, which have a common function expressed in their ability to cause serious damage to oil and gas fields and other types of economic activity carried out at the sea [11]. Our approach is based on the analysis of the data concerning, on the one hand, release of fluids of the earth's crust, i.e. groundwater (including metal-bearing solutions), mud, oil and gas, and on the other hand, catastrophic ice processes in the northern area of the sea We use as one of the illustrative examples, a very sad and little-known because of its secrecy, experience of the "ice battle" in the Caspian in the winter of 1953.

\section{Standards for Study and Prevention of Natural Accidents in the Caspian Sea}

Though the number of natural accidents at offshore oil and gas fields is growing every year, a methodology for their forecasting has not yet been developed. Even after a detailed study of the structural geology and lithology of deposits using modern methods of marine geophysics and exploration drilling, opening of oil and gas deposits is carried out to a large extent blindly, without accurate knowledge of the geomechanics of the rock mass and the regime of reservoir fluids. In addition, it is now becoming increasingly apparent that the danger of reservoir fluid blow increases in proportion to the aging of oil fields and is most characteristic of abandoned ones. But, unfortunately, effective methods of escaping such a danger and "reclamation" of outdated fields are unknown. This generally abnormal situation is enshrined in the "Safety Rules in Oil and Gas Industry" (SR 08-62403), which impose very strict requirements of the Russian Gosgortekhnadzor to the well construction (Section 2.2), as well as to the prevention of open flowing of wells (Section 2.7.7). But they do not indicate specific ways of implementing such strict requirements.

The gap is observed in the state environmental acts: They also do not stipulate an algorithm for practical actions in abandoned marine fields. Therefore, following such run around and vague "rules", field personnel are forced to act at their own risk, hoping for success in the scientific search for reliable ways to predict dangerous processes in the depths of seas.

Current trends of supporting the environmental safety of marine activities are usually based on the notion that the main sources of oil pollution of the seas are external, which include operations at oil terminals, tanker accidents, operational discharges from oil-containing waste ships, accidental oil spills on drilling platforms, etc. [12]. Therefore, the marine environment control system adopted in our country and abroad still proceeds from the fact that the so-called zero discharge technology is supposedly able to fully ensure the safety of offshore oil and gas production. Thus, in particular, the Law of the Russian Federation "On Minerals" (Article 24) requires users of mineral recourses to strictly comply with the "Oil and oil product spill prevention and response plan" (OSPRP), as well as the requirements for Maximum Permissible Concentrations (MPC) of polluting substances in the marine environment (Decree of the Government of the Russian Federation No. 613 dated 08/21/2000, as amended on April 15, 2002, No. 240).

In fact, neither the technology of zero discharge, nor the POPSR and the MPC requirements fully ensure the safety of a number of offshore oil and gas fields, since they unreasonably exclude any other types of danger. These are sudden releases from the depths of the seas toxic fluids (groundwater, oil and gases) or the so-called griffins, which are usually accompanied by geodynamic movements of the depths: Earthquakes, subsidence or swelling of the seabed, underwater landslides, etc. Fountain hydrocarbon emissions (most often gaseous) account for $44.7 \%$ of the accidents and disasters in offshore 
fields. Most of these emissions (57\%) result in ignition. In this case people die, drilling rigs and offshore oil fields are destroyed [13,14]. According to Rostekhnadzor, in recent years on lands in Russia the average number of uncontrolled emissions has been 5.5, and explosions and fires - 5.1[15].

In the context of the current expansion of the oil and gas industry on the Caspian shelf, there is a great need for reliable forecasts of accidents [12]. In this connection the Institute of Oceanology RAS (Russian Academy of Sciences), in common with the Institute for Dynamics of Geospheres RAS, Engineering and Technology Center "ScanEx", Roscosmos, Rosprirodnadzor, Institute of Oil and Gas Problems RAS, Institute of Geography RAS, Institute of Water Problems RAS, Moscow State University, Research Center for Space Hydrometeorology "Planet" and other organizations have joined in conducting multilevel environmental and geodynamic monitoring of shelf areas involved in the development of oil and gas resources of the Caspian Sea. The arsenal of modern monitoring methods and technical equipment used by the Institute of Oceanology RAS includes ship, underwater, satellite, seismological and stationary observations using bottom and buoy stations.

A number of documents serve as the basis for such studies: The Framework Convention for Protection of the Marine Environment of the Caspian Sea (Tehran Convention) for the conservation of the marine and coastal environment of the Caspian Sea and prevention of its pollution, the Marine Doctrine of the Russian Federation for the period up to 2020, approved by the President of the Russian Federation on July 27, 2001 (Order No1387), as well as the Protocol of the meeting of the Maritime Board under the Government of the Russian Federation of October 28, 2005 "On the creation of an comprehensive security system for oil and gas complexes on the continental shelf". This protocol prescribed, in particular, use of offshore drilling platforms as technological carriers for a comprehensive multilevel environmental and meteorological monitoring system, and in seismically active zones for geodynamic monitoring [15].

The main elements of a multi-level system, i.e., satellite, above-water, underwater, borehole and ground-based geodynamic monitoring have already been introduced and are performed in offshore oil and gas fields in the Caspian Sea, which are oper- ated by the oil company LUKOI (Open joint stock company). Following the recommendations of the State Ecological Expertise of Rosprirodnadzor, the company's management, in collaboration with the Institute of Oceanology RAS in 2012, for the first time in our country approved the "Regulation of geodynamic monitoring" at the field named after Yu. Korchagin. Currently Lukoil is implementing such regulations in other Caspian offshore fields. Work is much weaker in organizing climate-glaciological studies of the occurrence, process and consequences of natural disasters similar to the 53 "ice battle" in the North and Middle Caspian. Meanwhile an assessment of the intensity of ice and other hydrometeorological impacts that belong to the category of hazardous natural processes can be referred to a key link in the entire system for ensuring the industrial and environmental safety of oil and gas facilities in the Caspian Sea.

The complexity of the problem to be solved is determined, firstly, by the poorly studied windwave and ice impact on the Caspian oil and gas fields and, secondly, by the multifaceted nature of the tasks being solved due to the extremely high variability of the sea level position and ice cover of the Caspian Sea $[3,16]$. It is known that fluctuations in the level of the Caspian Sea reaching several meters during the estimated period of operation of hydraulic structures can lead to a significant redistribution of depths. Accordingly, the conditions for the formation of ice ridges and their impact on the objects of the marine economy are changing $[5,6,11]$. A separate problem is in the secrecy of the materials required for professional analysis, diagnosis and prediction of catastrophic ice events in the Caspian $[17,18]$.

\section{Sudden Emissions of Mud, Oil and Gas from the Depths}

Data on such natural disasters has been known since ancient times. An indicative example is the catastrophic collapse of the "60 Years of Azerbaijan" Self-propelled floating drilling rig (SPFDR) that occurred on September 9, 1983 near the eastern coast of the Middle Caspian. The drilling point was located in $23 \mathrm{~km}$ from the Cape Rakushechny, where the sea depth is $43 \mathrm{~m}$. The calculated drilling depth was $4500 \mathrm{~m}$. At a depth of $445 \mathrm{~m}$, during the drilling of Oligocene clays, the washing fluid was interrupted by a breakthrough of gas-saturated formation fluids, and a sharp rise of mud solution 


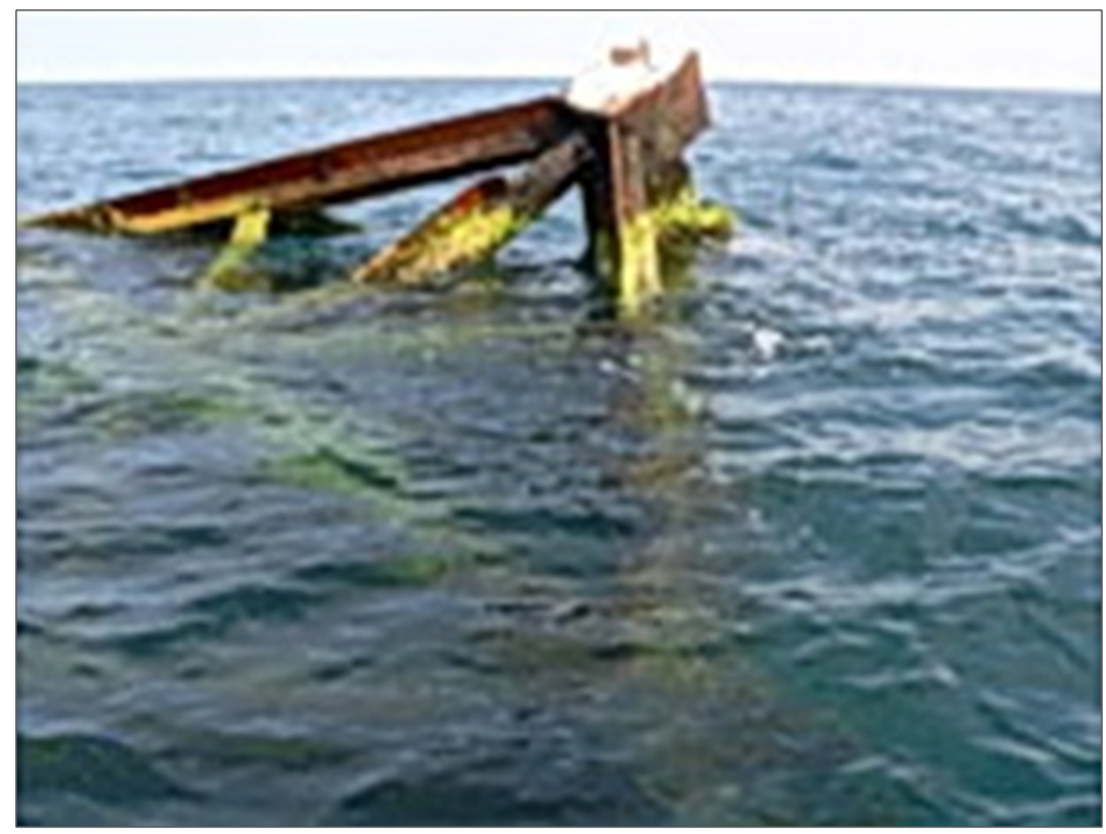

Figure 2: A recent snapshot of the accident site of the "60 Years of Azerbaijan" SPFDR.

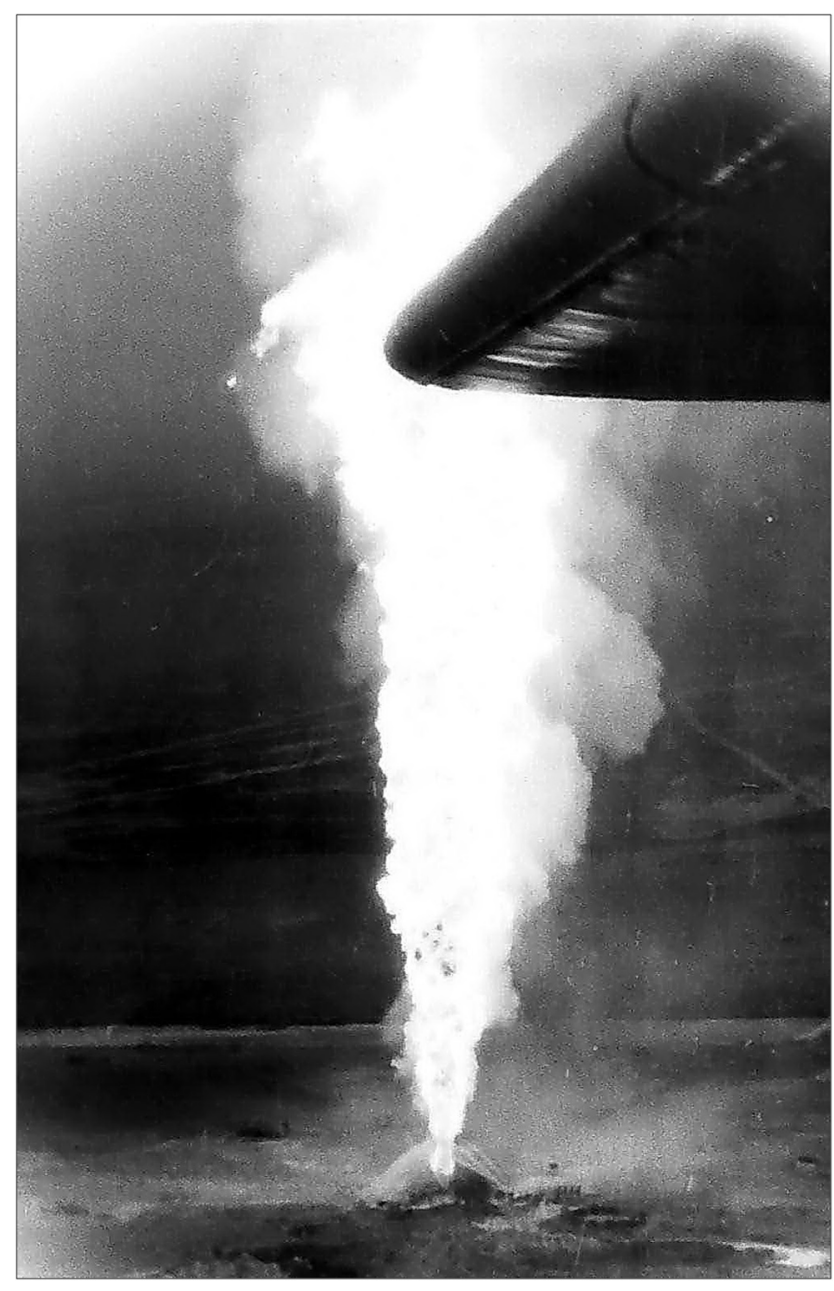

Figure 3: Burning oil fountain at the "Tengiz" field. (The Aerial photograph was taken by P.I. Bukharits in from a height of $150 \mathrm{~m}$ ). from the interesting space began. A gas fountain rose from a well to a 50-meter height and an intensive washout of soil began under one of the supports of drilling rig system. As a result the derrick shifted and crashed down (Figure 2). The accident at SPFDR "60 years of Azerbaijan" occurred at night in stormy weather. Two people died. The vessels arrived in time all night catching people from the water. Then the rescuers set fire to the gas so that it would not poison the atmosphere. A few days later the torch went out.

Another example is the accident at the "Tengiz" field in Western Kazakhstan (northeast coast of the Caspian Sea), which occurred on June 24, 1985. On this day, a powerful burning fountain of oil and natural gas saturated with hydrogen sulfide burst from a well of about $5 \mathrm{~km}$ from well No. 37 under a pressure of almost a thousand atmospheres. The fountain rose up to a height of more than $200 \mathrm{~m}$, throwing a multi-ton string of drill pipes from the well to the surface and turning them into "pasta". At the same time, the nearby buildings were destroyed, and the fire raged for several months (Figure 3).

A team of liquidators was thrown into the fight against the accident, equipped with heavy-duty air transport for the delivery of equipment worth \$2 million from the European warehouse "Cameron". The accident was eliminated only after four hundred days. As a result, plans to increase oil production in Kazakhstan from 18.7 million tons in 1981 

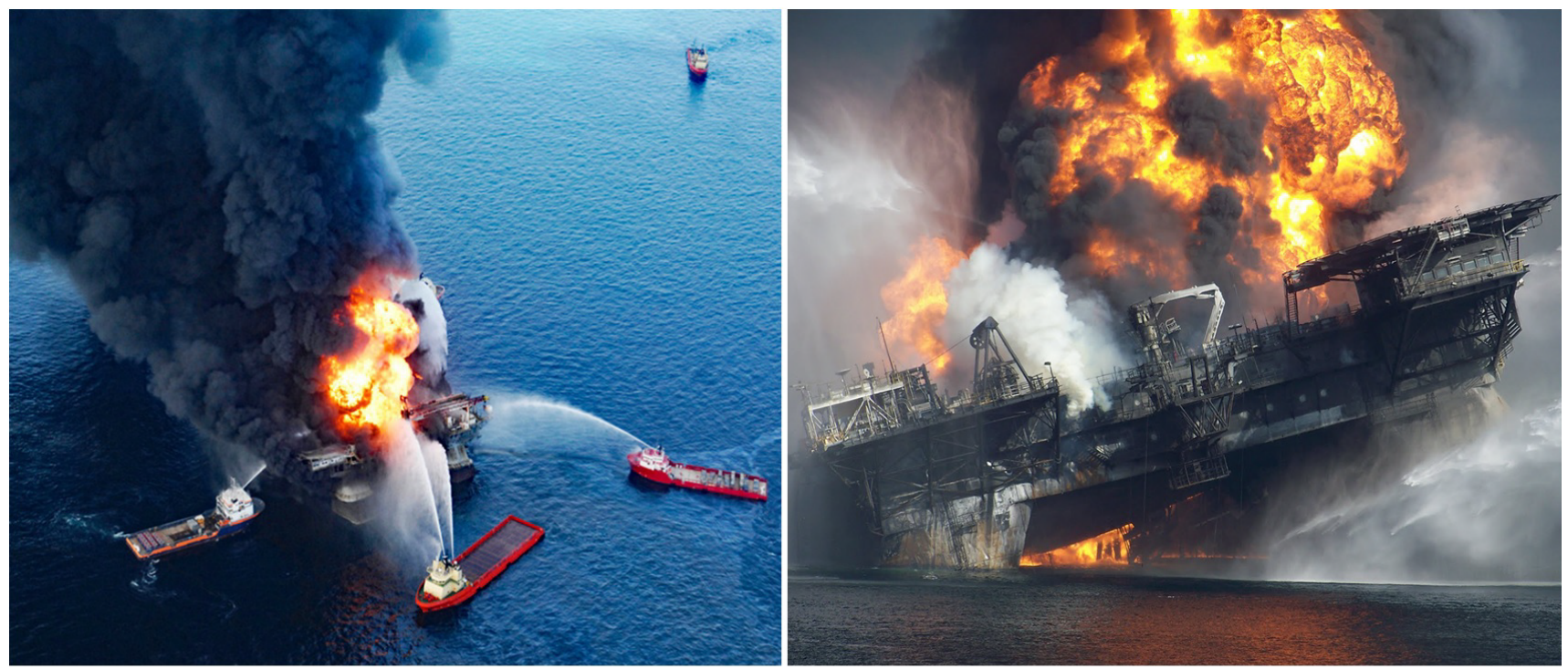

Figure 4: Extinguishing of fire on the oil platform in the Gulf of Mexico, April 21, 2010 (Photos from Yandexpictures).

to 25 million tons in 1985 were disrupted. This exacerbated the problem of a drop in oil production in the USSR that emerged in the 70s. According to some researchers, in the foreseeable future such an outburst of high-pressure reservoir fluids from the subsalt structural level of the southern edge of the Peri-Caspian Lawland may also occur in the Northern Caspian at the Kashagan field [4].

Not so long ago a new similar accident occurred in March, 2019 at the well of the Kalamkas field, located in the Mangistau region of the Republic of Kazakhstan, four kilometers from the Caspian Sea. Around the drilling site, 13 griffins formed - sudden breakthroughs to the surface of fluids (most often gas), moving under great pressure through the annulus of the boreholes. The accident was accompanied by a fire, which was completely eliminated only on April 4, 2019. The task of thoroughly studying the experience of dealing with major accidents on cross-border oil platforms is of particular importance. Thanks to television and the Internet, great many people became aware of the accident that occurred on April 20, 2010 at the Deepwater Horizon oil platform in the Gulf of Mexico (Macondo field) [19]. The platform got inflamed at 80 kilometers off the coast of Louisiana (USA), killing 11 out of 126 oil workers on it (Figure 4).

On the second day after the explosion, this platform sank, having appeared on the seabed at a depth of about $1,500 \mathrm{~m}$. Over the next six months, about 5 million barrels of oil spilled into the waters of the bay from its depths. To eliminate the consequences of the tragedy, British Petroleum Corporation spent a colossal sum of $\$ 42$ billion. It should be noted that the subsequent oil spill became the largest in the US history and turned the accident into one of the largest technological disasters with a negative impact on the environment (Figure 5).

The blockage of a deep well in the Gulf of Mexico required a tremendous strain of intelligence, technical and organizational capabilities with attraction of achievements of underwater robotics. All in all 5 thousand vessels and 40 thousand people participated in the operation. They started drilling of two discharge wells. Moreover, shutting-in of the well did not solve the problem of pollution control of the bay and the coastal zone. This problem stretches over many years and involves huge financial costs. The accident in the Gulf of Mexico is a serious warning to all oil companies which, in the pursuit of profit, are ready to take significant risks by mining offshore [19]. Obviously, repeat of such an accident in the Caspian Sea can turn this sea into a complete zone of environmental disaster.

\section{Catastrophic Drift of Ridged Ices}

The icebattle of 1953. Estimation of degree of impacts of ice formations in the northern part of the Caspian is an important aspect in ensuring the safety of hydrotechnical structures built in the water area of this sea $[20,21]$. The development of oil and gas resources of the Caspian Sea dictates the need for thorough study of ice impacts on hy- 
Dilution Factor for dye injected within $20 \mathrm{~m}$ of surface Dye injected continuously for 2 month period

Days since spill: 66

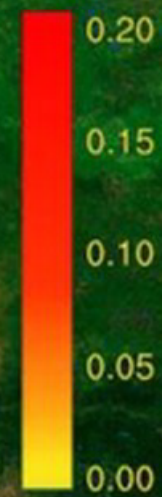

Gulf of Mexico

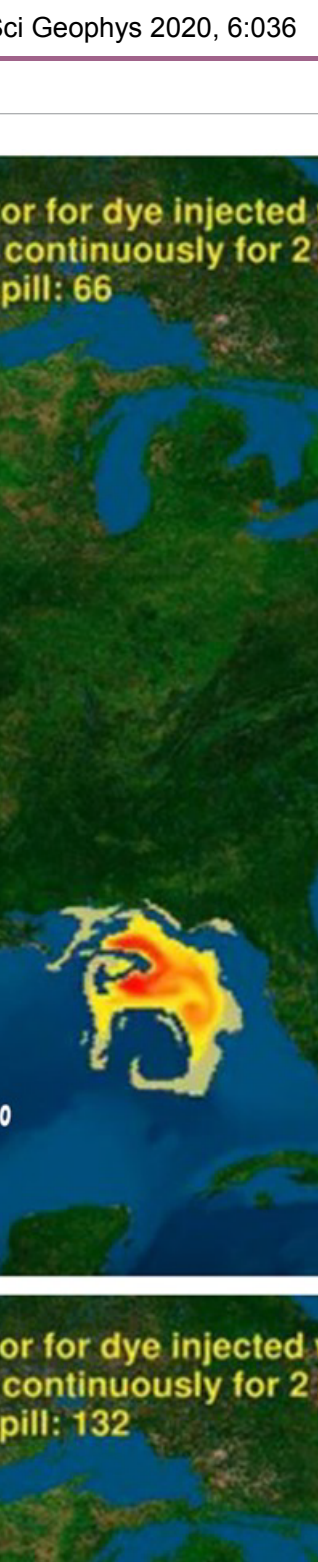

Atlantic Ocean

Dilution Factor for dye injected within $20 \mathrm{~m}$ of surface

Dye injected continuously for 2 month period

Days since spill: 132
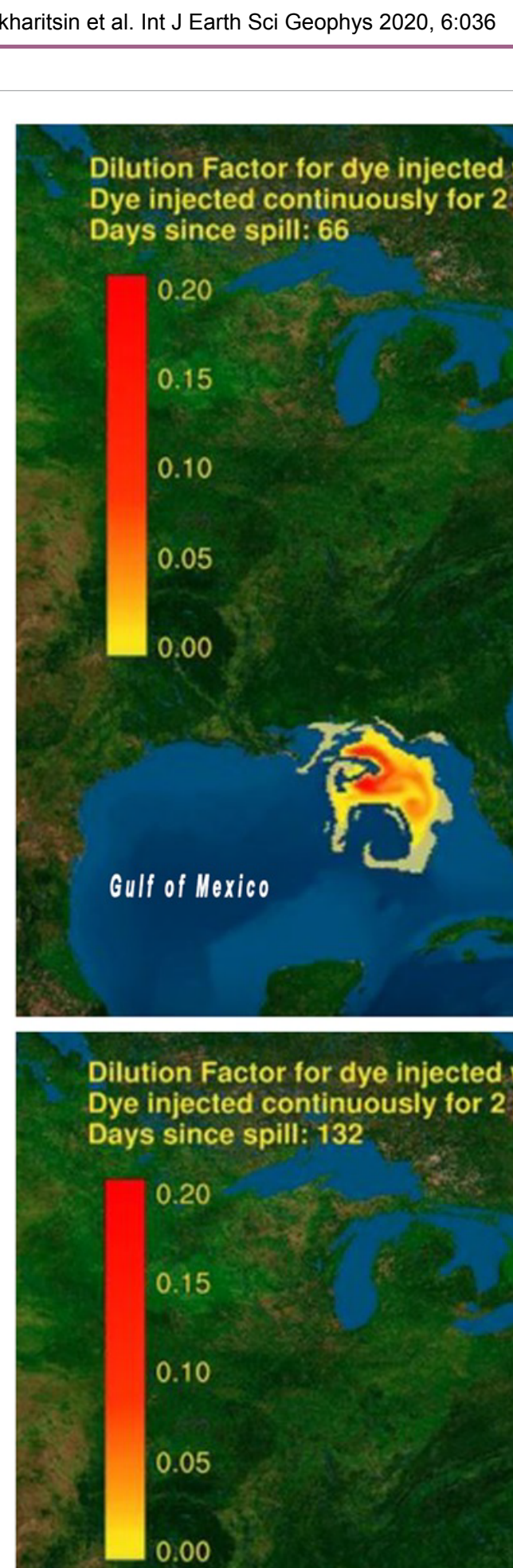


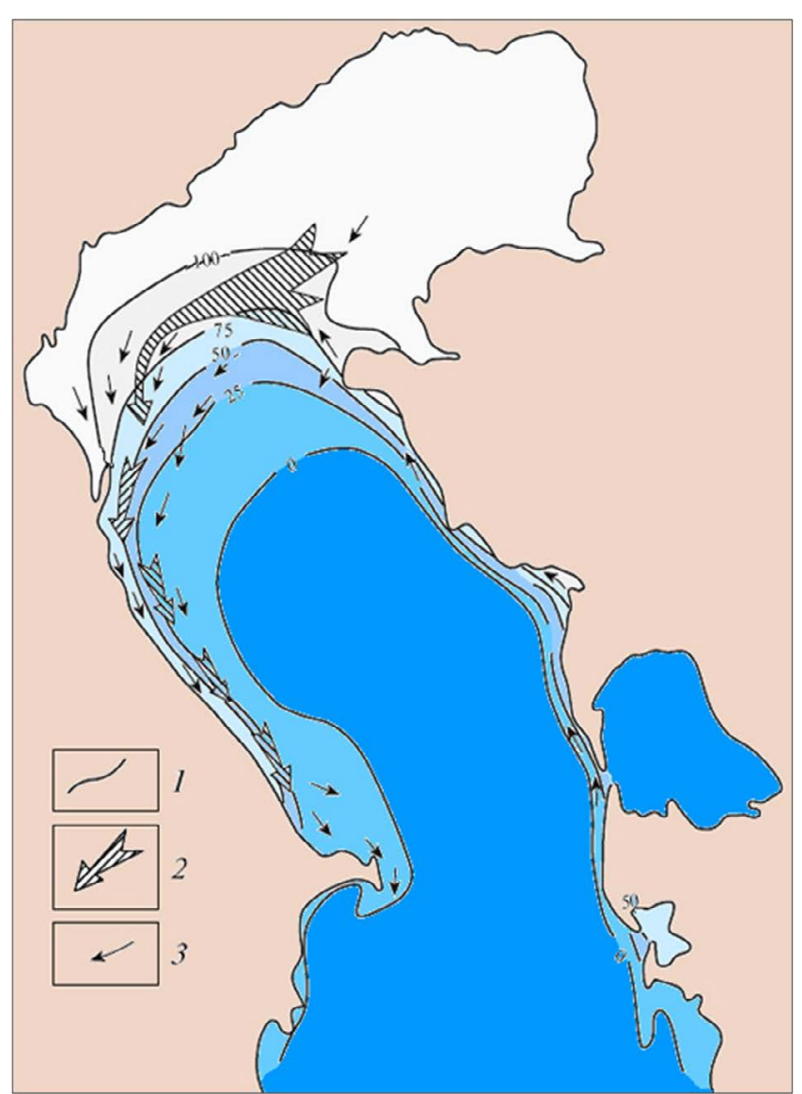

Figure 6: The probability of ice formation and directions of ice drift (Source: [24]).

(1) The contour of the probability of ice formation \%; (2) General direction of drift; (3) Prevailing direction of drift.

drotechnical systems $[5,18]$. However, inferential research of the catastrophic drift of ice ridges is important, taking into account the laws of hydrodynamics of the Northern and Middle parts of the Caspian sea (Figure 6).

The lack of reliable estimates of the intensity of the impact of ice ridges on the environment can lead to damage to engineering structures, including subsea pipelines and oil platforms. Thus, great cognitive value has the description of events that occurred in the western coast of the Caspian Sea in the winter of 1953 and were first published in the open press in the article by Artyom Simonyan ("Science and Life", No. 6, 2002), who in those years worked as the chief engineer of the project of marine hydraulic structures at the "Gipromorneft" Institute [17]. He tells that in consequence of sharp warming in the northern part of the Caspian Sea, huge ice fields broke away from the fast ice and, driven by wind and sea current, sailed south. The first obstacle to the ice floe was the Izberbash field
(Figure 7).

Understanding the complexity of the situation, the government of the Dagestan Autonomous Soviet Socialist Republic decided to bombard the ice on the far approaches to the oil field and sprinkle the ice shell with coal powder for more intense melting. But neither one nor the other helped. The ice shell tightly squeezed the structures of the Izberg-Sea, and its destruction began. "The piers and platforms one after another fell apart like houses of cards. There were no icebreakers in the Caspian at that time, and even if they were, they could not cope with the force of nature. Two days later, only distorted fragments of structures stuck over the ice floes", - writes A. Simonyan [17]. To a lesser extent the piers of the Inchkhe-Sea deposit, located a few kilometers from the coast, were destroyed.

The ridged ice quickly moved south, and two days later a real ice battle began on the oil-producing piers of the Apsheron peninsula. When the ridged ice began to demolish the supports of piers, the military began to use explosives. The ice crumbled at the supports, passing part of the ice under them, but it immediately began to crush with renewed vigor and the spans went under water. Thus, huge sections of piers of 300-400 meters long with pipelines laid along them, power cables with lighting poles and platforms with operating wells slowly went to the bottom of the sea. Fortunately the oil workers managed to kill the wells and prevented the oil spill. Ice floes destroyed the oil fields of Artem-Sea, Gyurgyany-Sea and moved towards the Oil Rocks. This was the worst test for the oil industry, perhaps, in the entire history of their offshore production in the Caspian.

Weather reports daily convinced that the tragedy is inevitable for the Oil rocks. The management of the oil field decided to shut off the existing wells and send all personnel to the shore: Drillers, operators, electricians, builders, and doctors. There were only 50 officers on duty. This was a team consisting of firefighters and workers, two meteorologists, two radio operators and two specialists from "Azmorneft". They were faced with the task: To prevent a fire and if and when the structures collapsed, retreat to the south side of the oil field, where three torpedo boats of the Caspian flotilla were waiting for them in clear water. When the ice floes came into contact the first object of the Oil Rocks, a completely unexpected thing happened: The wind, 


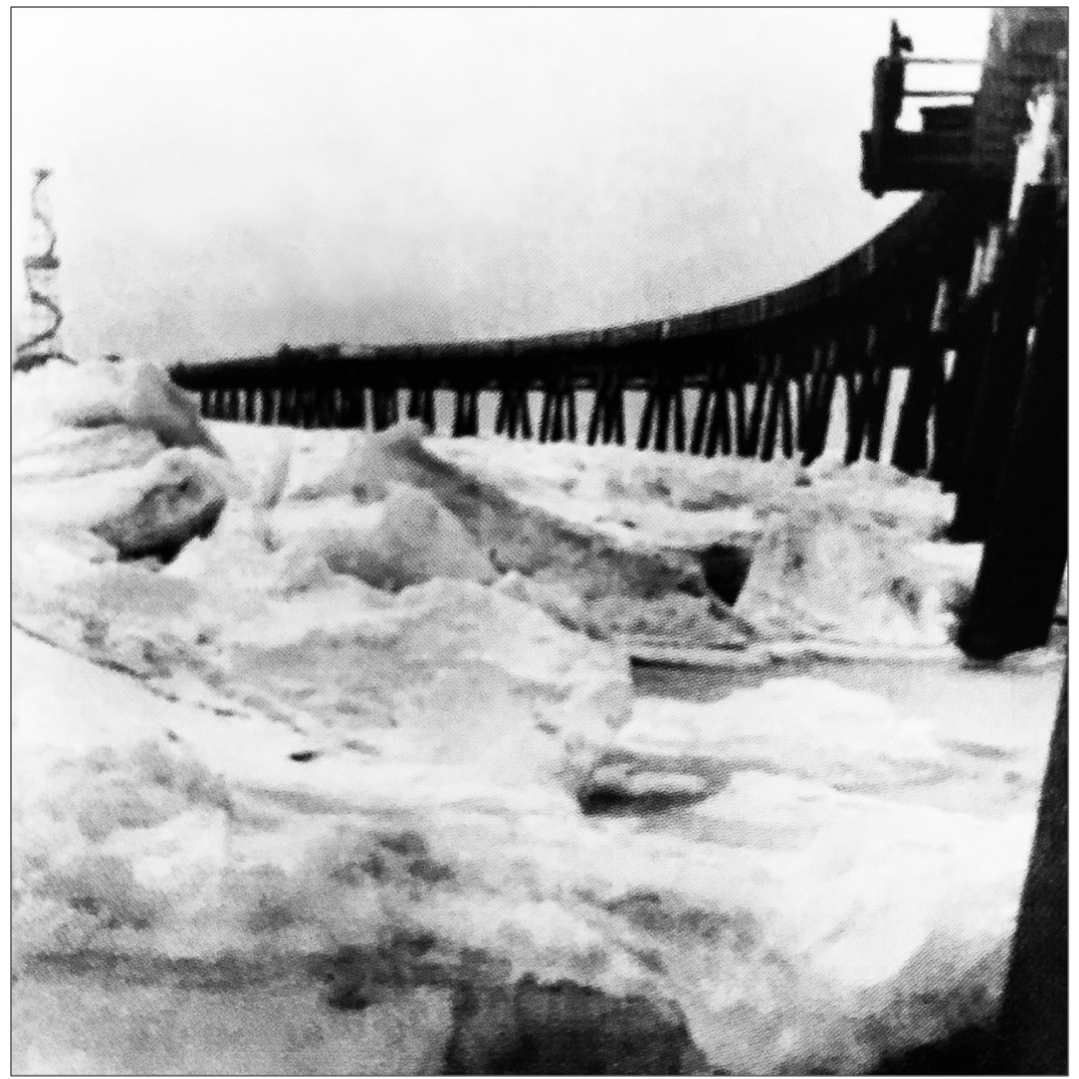

Figure 7: Ice ridges on the approaches to the piers of the Izberg-Sea oil field in February 1953 (Photo from the archive of "Rosneft-Dagneft" OJSC).

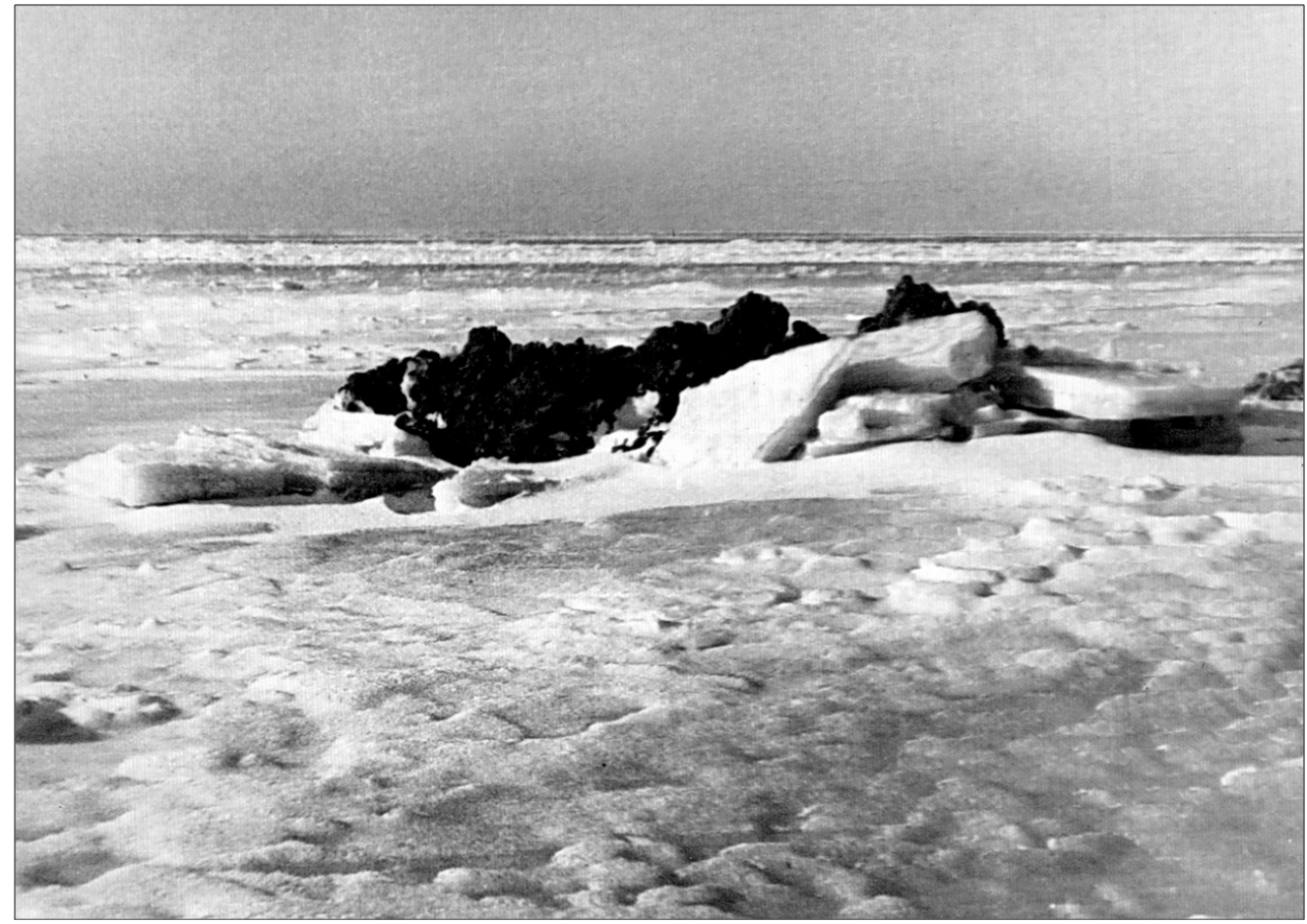

Figure 8: The ephemeral islet formed as a result of the plowing action of ice (Photo by F.I. Waller).

blowing for many days from the east, instantly died down, and then, rapidly gaining strength, it blew out from the west. The ice stopped for a short while and sailed to where it came from. It warmed 
sharply, and they began to melt quickly. The people did not expect such an event. They were convinced that the tragedy on the Oil Rocks is inevitable [17].

After the "ice battle", drillers and builders had arush season. They began to restore lost wells, piers, sites and other hydraulic structures. Simultaneously they began to repair wells. And half a year later all the oil fields of Apsheron went into action newly. Oil production reached its previous level and quickly even exceeded it. As for the Izberg-Sea field they decided not to restore it because of the poverty of the oil-bearing layer.

Unfortunately, climate-glaciological studies of the occurrence, process, and consequences of hazardous natural processes in the Caspian, similar to the "ice battle" of 1953, have not yet been practically carried out.

The effect of drifting ice on shipping. All information on the ice thickness of the Caspian Sea, obtained as a result of long-term observations, is data on natural (thermal) build-up ice. The maximum thickness of such ice in the Northern Caspian is observed in January-February. But even in very severe winters its natural thickness, as a rule, does not exceed $50-60 \mathrm{~cm}$ in the northwestern and 80$90 \mathrm{~cm}$ in the northeastern part of the sea.

As experience shows, in the Caspian Sea ice cover is most often found in the form of pods and layers, the thickness of which significantly exceeds the thickness of the ice of natural growth. Strong winds, especially in the initial period of its formation contribute to the break-in of fast ice, drift and intense movements of floating ice. With thickness of 1 to $30 \mathrm{~cm}$ multifold laying of the ice takes place. The areas of the most intensive shifts in the North Caspian include the Astrakhan Sea Raid and the marine part of the Volga-Caspian Canal.

In mild and moderate winters the thickness of layered ice mainly depends on the wind, and in severe winters the influence of wind is weakened due to strong fast ice. Due to the shallow water and significant fluctuations in the level of the Caspian sea because of non-periodic water Raising-Lowering processes using wind, the ridged ice interacts with the bottom, forming gouging channels $[5,6]$. The width of such gouges varies from a few meters to 50-100 m or more. All gouges end in shafts formed by plowed soil. The height of some gouges exceeds the depth of the sea and they reach the surface in the form of islands (Figure 8).

Plowing gouges, light against the background of a darker bottom are clearly distinguishable from an airplane. A large number of gouges are observed in the North Caspian in spring, after cleansing from ice, when the water has not yet been stirred up by spring storms. Their density reaches $20-50$, and in some places of 100 or more gouges per $1 \mathrm{~km}$ of the route. The duration of the existence of gouges in muddy soils is 2-3 years; in sandy soil, furrows are washed away by wave agitation for one season. Ice drift often leads to dramatic situations in the marine part of the Volga-Caspian Channel. During a sharp increase in the east and north-east winds, large masses of ice break away from the ice field in the central part of the North Caspian and begin to move to the west coast. At the same time, serious threats arise for ships moving along the marine part of the Volga-Caspian Channel. So, in February 1981, a large bulk carrier "Baku" with a displacement of 7 thousand tons was going along the channel. As a result of the wind-driven surge of sea water in the area and the impact of drifting ice, the bulk carrier was moved to a distance of more than $10 \mathrm{~km}$ from the fairway of the Volga-Caspian Channel. The icebreakers serving the Channel could not help the bulk carrier. The small-sitting tugboat, which was sent to the rescue, did not have enough strength to pull the bulk carrier aground (Figure 9). After the end of the surge wave and the freezing of the ice, the "Baku" bulk carrier was stuck in the shallow water of the North Caspian for a long time.

In those years, in order to facilitate carrying out the maritime operations, attempts were made to artificially crack ice in the Volga-Caspian and Ural-Caspian shipping canals. However, these measures did not give positive results, as the broken ice was shifted to the offshore part of the canals, where the flow velocity decreased, and the ice floes began to clog their channels, creating insurmountable obstacles for ships. In addition, frequent winds of the eastern and southeastern directions tore off and brought out new ice from the sea, which completely blocked the passage of ships and icebreakers into the sea for a long time. Thus, the practice of artificial ice breaking with the help of icebreakers in canals and shallow waters of the Northern Caspian had to be abandoned.

Destruction and ignition of the underwater gas pipeline. During the spring flood on the sea reach 


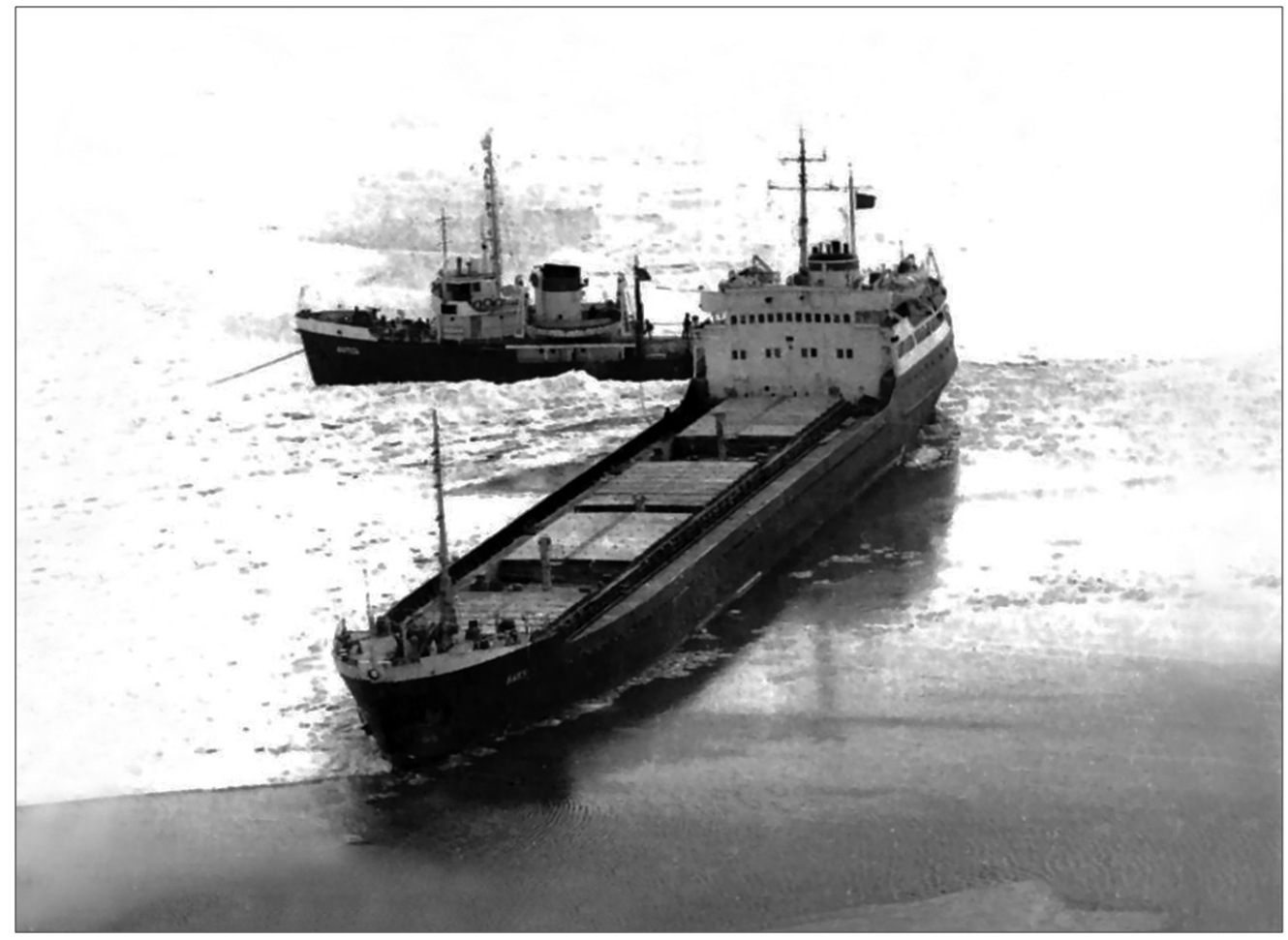

Figure 9: The cargo ship "Baku" in shallow water on February 18, 1981 (Photo by P. I. Bukharitsin).

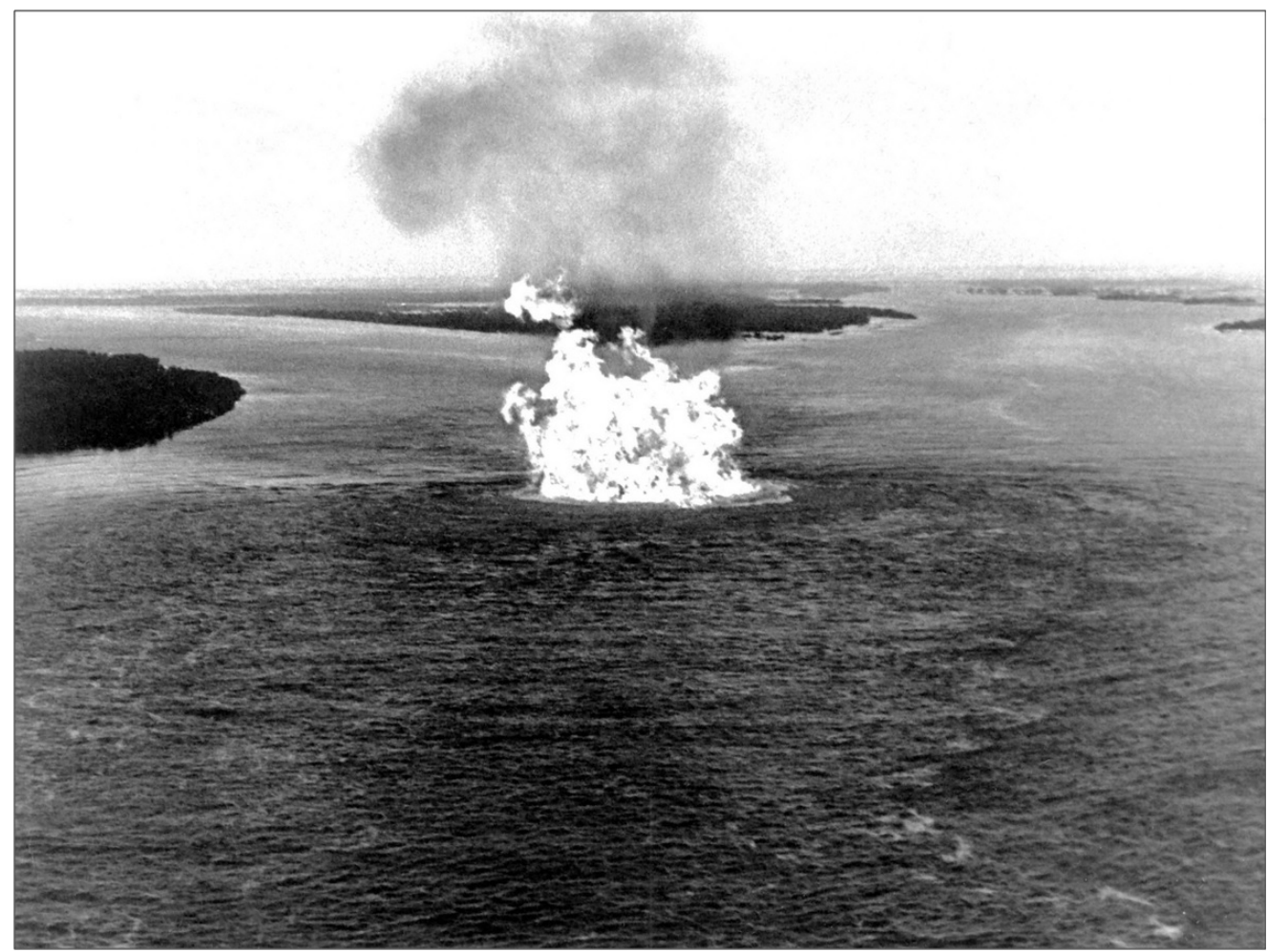

Figure 10: Fire gas pipeline on the Volga River in the area of the village of Rechnoye (Photo by P. Tsikunov).

of the Volga River (Astrakhan Region), the watercourse washed away the poorly deepened and fixed pipeline on the river bottom. The gas pipe appeared to be suspended in a powerful stream of water and burst at the junction. Gas began to gush under pressure. At this moment, a hydrofoil boat was passing by and a spark flying out of the exhaust pipe of this vessel ignited an explosive gas 
mixture. There was a powerful explosion, as a result of which the ship was thrown out on the bank by wave. Fortunately, people on the ship were not injured. The residents of the neighboring village of Rechnoye were also lucky: The wind blew in the opposite direction from the village, and there was no fire on the shore. Despite the fact that the gas pipeline was quickly blocked on both sides, the gas remaining in the pipe was burning out for many hours (Figure 10).

\section{Discussion}

With the rapid growth of oil and gas extraction works and the increase of their impact on the environment, there is a need to justify new technical approaches that ensure reliable forecasts of the immediate and long-term consequences of the interaction of natural and production systems.

In geoecological studies of oil and gas development in the Caspian Sea, it seems to us timely to apply the approach that integrates geological and geographical knowledge and thus contributes to their mutual enrichment. The main aspects of such studies of oil and gas production in the Caspian are shown in the Table 1.

The Table 1 shows that, hazardous hydrometeorological processes compared with geological ones represent a wider range of threats to offshore oil and gas production. But, on the other hand, eruptions and ignition of fluids occur, as a rule, very unexpectedly and are accompanied by destructive explosions and proceed rapidly. Therefore, it is customary to regard the prediction of dangerous exogenous-geological processes within the shelf sections of hydrocarbon exploration or production as a more popular scientific and practical task. In our opinion, an equally serious approach to organizing and conducting research on hazardous processes of both geological and hydrometeorological genesis is required.

\section{Conclusions and Recommendations}

The existing research experience and instrumental observations of the development of oil and gas deposits in the Caspian sea water area convince us of the need to implement a parametric approach to geographical analysis and to predict the impact of hazardous natural processes on such developments.

On the one hand, it is necessary to significantly expand the front of scientific research aimed at preventing explosions and fires from gushing fluids in the oil and gas fields, often leading to destruction of drilling rigs and stationary oil platforms on the coast and at sea, as well as to sinking of floating oil platforms in the deep zone of the Caspian shelf.

Table 1: Parameters of hazardous natural processes in the zones of development of oil and gas deposits of the Caspian Sea.

\begin{tabular}{|c|c|c|}
\hline \multirow{2}{*}{$\begin{array}{l}\text { Objects of production and } \\
\text { transport }\end{array}$} & \multicolumn{2}{|c|}{ Disasters arising under the influence of natural factors: } \\
\hline & The eruption of fluid & Storm surges and ice drift \\
\hline $\begin{array}{l}\text { Stationary oil platform on the } \\
\text { coast and at sea }\end{array}$ & $\begin{array}{l}\text { Ignition and complete } \\
\text { destruction of the facility }\end{array}$ & $\begin{array}{l}\text { Wind-driven flooding and wave destruction of the } \\
\text { object; blockage and partial destruction of the } \\
\text { object by ice mass }\end{array}$ \\
\hline Floating offshore oil platform & $\begin{array}{l}\text { Fire, complete } \\
\text { destruction and sinking of } \\
\text { the object }\end{array}$ & $\begin{array}{l}\text { Wind-driven flooding, wave destruction and sinking } \\
\text { of an object; destruction and sinking of the object } \\
\text { by drifting ice }\end{array}$ \\
\hline Bottom pipeline & $\begin{array}{l}\text { Ignition and complete } \\
\text { destruction of the facility }\end{array}$ & $\begin{array}{l}\text { Destruction of an object by the underwater part of } \\
\text { ice ridges, as well as its probable ignition }\end{array}$ \\
\hline $\begin{array}{l}\text { Marine vessel, in particular, oil } \\
\text { and gas loading }\end{array}$ & $\begin{array}{l}\text { Inflammation, complete } \\
\text { destruction and sinking of } \\
\text { the object }\end{array}$ & $\begin{array}{l}\text { Moving of an object in shallow waters under the } \\
\text { conditions of a surge wave; destruction and sinking } \\
\text { of an object in a big wave; destruction and sinking } \\
\text { of an object by drifting ice }\end{array}$ \\
\hline $\begin{array}{l}\text { Costal and marine } \\
\text { hydrotechnical construction: } \\
\text { piers, breakwalls, dams, } \\
\text { bundwalls }\end{array}$ & $\begin{array}{l}\text { Fire, complete or partial } \\
\text { destruction of the object }\end{array}$ & $\begin{array}{l}\text { Destruction and sinking of an object; destruction } \\
\text { of communications and equipment located at the } \\
\text { facility. }\end{array}$ \\
\hline
\end{tabular}


On the other hand, it is required comprehensive studies of the laws and features of the occurrence of storm surges in the Caspian Sea and the catastrophic drifts of ridged ice caused by them which leads to the destruction and sinking of various objects of oil and gas field activity: Stationary and floating oil platforms, oil and gas vessels, bottom pipelines and other coastal and marine hydrotechnical facilities and structures.

The results of our study allow us to formulate a number of most common practical tasks for overcoming, or at least mitigating, the danger of catastrophes, on the one hand, of a geological and, on the other hand, hydrometeorological nature:

- Organization and implementation of satellite monitoring of the appearance of oil stains on the surface of the Caspian Sea;

- Improving the reliability of scientific forecasts of accidental displacements and sudden releases of formation fluids in offshore oil and gas fields;

- Development of the scientific basis for predicting and preventing disasters caused by storm movements in winter in the south-western and southern directions of the ice masses of the North Caspian;

-Ecological and economic justification of transportation routes and the use of ports for transshipment of oil and gas products in the North and Middle Caspian, taking into account the threat of catastrophic effects of drifting ice.

\section{Acknowledgements}

The authors are grateful to the Ministry of Natural Resources and Ecology of the Republic of Dagestan and the Environmental Management and Environmental Protection Service of the Astrakhan Region for information support of this study.

\section{References}

1. http://vsegei.ru/ru/conf/summary/gorgeol-17/ prezent/26-09_23.pdf

2. Buharicin PI (2018) Non-fictional stories (notes oceanographer). "Sorokin Roman Vasil'evich", Astrahan': Izd, 184.

3. Buharicin PI (1988) Difficult oil the North Caspian. Man and the Elements 89: S105-S107.

4. Buharicin PI, Golubov BN, Ivanov A Yu (2016) Features of hydrology and structure of subsurface marine deposits of the Caspian sea. Methods of prediction and monitoring of reservoir fluid emissions in the conditions of expansion of offshore oil and gas production. Werlag: Palmarium Academic Publishing, Russia, 110.

5. Buharicin PI, Ogorodov SA, Arhipov VV (2015) Impact of ice formations on the bottom of the North Caspian sea in the conditions of fluctuations of the level and ice cover. Vestn Mosk un-that ser 5 Geography 2: 101-108.

6. Valler FI (1973) Ice conditions in the North of the Caspian sea in a very severe winter 1968-69. Ice Research of the Southern Seas of the USSR. M.: Science 124.

7. (1979) Astrakhan Ice Service, 1927-1997. Aerial Ice Reconnaissance reports from 1979, Astrakhan.

8. Chen JL, Pekker T, Wilson CR, Tapley BD, Kostianoy AG, et al. (2017) Long-term Caspian Sea level change. Geophysical Research Letters 44: 6993-7001.

9. http://www.caspcom.com/index.php?razd=sess\&lang $=1$ \&sess $=17$ \&podsess $=61$

10.El'darov EM (2017) The parametric dimension of the Y.A. Vedenin's space-temporal concept of tourism. In the Focus of Heritage. M: Institute of Geography S469-S477.

11.(2001) Problems and prospects of a sea-economic complex formation in Dagestan. Otv. red. Z.K. Yuzbekov, E.M. El'darov. Mahachkala, DNC RAN, 122.

12.Ismailov Ch N, El'darov EM (2009) Dagestan in the petrochemical complex of the Caspian region. Regional Problems of Economic Transformation 4: S142-S148.

13.Golubov BN, Ivanov A Yu (2014) Hydrometeorology and hydrochemistry of the seas. Earth from space, Issled, 2: S62-S81.

14.Lobkovskii LI, Levchenko DG, Leonov AV, Ambrosimov AK (2005) Geoecological monitoring of offshore oil and gas areas. Otv. Red. S.S. Lappo M, Nauka. 326.

15.Bogoyavlenskii VI, Bogoyavlenskii VI (2014) Emergencies in the development of oil and gas resources in the Arctic and the oceans. Arctic: Ecology, Economics 4: 48-59.

16.(1996) Water resources of Dagestan: State and problems Repl. In: IM Saipulaev, EM Eldarov Makhachkala, West-Casp. BVU, 180.

17.Simonyan A (2010) Natural disasters in the Caspian. Proceedings of the Geographical Society RD 38: S17-S21.

18.El'darov EM (2017) What do we not know about the Caspian? Myths, legends and facts. Pavilion. 
19.http://www.ng.ru/ng_energiya/2010-09-14/11_ kaspiy.html

20.Buharitsin P, Ayazbayev E (2013) The role of drifting ice in building the bottom landscape and sediment composition in the shallow waters of north Caspian Sea. Materials of the $22^{\text {nd }}$ Intern. Conf. on Port and Ocean Engineering under Arctic Conditions (June 9-13, 2013, Espoo, Finland). Finland, Helsinki, 4.

21.Eldarov EM, Holland EC, Kamilov M-KB (2015) Oil and gas production in the Russian sector of the Caspian Sea: Public opinion on development paths and con- sequences. The Professional Geographer 67: 342350.

22.https://neftegaz.ru/news/drill/208091-rakushechnomu-mestorozhdeniyu-povezlo-lukoyl-namerentam-nachat-burenie-1-y-skvazhiny-uzhe-v-2021-g/

23.h t t p s: / / w w w. y o u t u b e.co m / watch?v=pE-1G_476nA\&feature=player_embedded

24.(1992) Hydrometeorology and hydrochemistry of the seas. Tom VI. Hydrometeorological conditions. SPb: Hydrometeoizdat, Caspian Sea, 1: 359. 